\title{
Erratum to: Least-Cost Modelling and Landscape Ecology: Concepts, Applications, and Opportunities
}

Thomas R. Etherington ${ }^{1,2,3}$

Published online: 6 May 2017

(C) Springer International Publishing AG 2017

Erratum to: Curr Landscape Ecol Rep (2016) 1(1):43-56. DOI 10.1007/s40823-016-0006-9

There was a typographical error in the original article in reporting the equations applying Pythagoras's theorem to calculate topographical distance. The corrected versions of Eqs. 4 and 5, and Fig. 5b are shown below.

\section{Equation 4:}

$e_{a, b}=\frac{c_{a}+c_{b}}{2} \times \sqrt{d_{a, b}^{2}+z_{a, b}^{2}}$

\section{Equation 5:}

$e_{a, b}=\frac{c_{a}+c_{b}}{2} \times \sqrt{d_{a, b}^{2}+z_{a, b}^{2}} \times v_{a, b} \times h_{a, b}$

The online version of the original article can be found at http://dx.doi.org/ 10.1007/s40823-016-0006-9

Thomas R. Etherington

t.etherington@kew.org

1 Royal Botanic Gardens Kew, Wakehurst Place, West Sussex, UK

2 Department of Zoology, University of Oxford, Oxford, UK

3 School of Environment, The University of Auckland,

Auckland, New Zealand

Figure 5b:

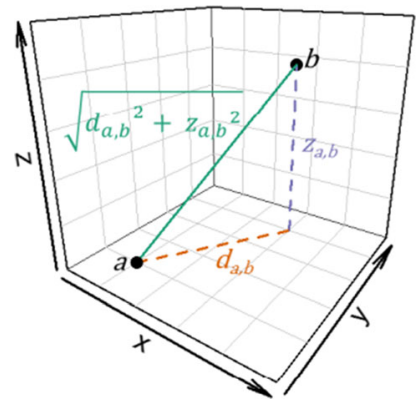

